\title{
Increasing of the liquid flow rate due to contrast wettability in the microchannel
}

\author{
Dmitry Gluzdov $1,2, a$ \\ ${ }^{1}$ Kutateladze Institute of Thernophysics SB RAS, 630090 Novosibirsk, Russia \\ ${ }^{2}$ Novosibirsk State University, 630090 Novosibirsk, Russia
}

\begin{abstract}
The global miniaturization leads to microchannels flows be perspective for novel cooling technologies. The problem of the drag reduction occurs in such systems. The twodimensional Poiseuille flow in microchannel with Navier slip condition is considered. The presence of bubbles with $1 \mu \mathrm{m}$ size on hydrophobic parts on the bottom wall of the channel is assumed for the problem. The calculations of the liquid flow rate and velocity depending on the slip length at the bottom wall have been done.
\end{abstract}

\section{Introduction}

Increasing the power of modern microprocessors is linked with the solution of problems with thermal regulators and the creation of a new type of cooling systems. The microchannels one or two-phase flow is seems to be perspective for novel cooling technologies. However, the problem associated with the drag reduction arises in such microchannels flow [1,2]. One of the solutions to this problem is use of micro-/nano-structured surfaces. It was showed that the grooves and cavities in the structure filled by a gas phase can reduce the viscous resistance of more than $40 \%[3,4]$. Note, that there is a problem with film rupture and instability in such systems [5,6,7,8].

Considering textured surfaces the term of effective slip length should be investigated [9]. As well as some possible effect inside a grooves, which can affect on the main flow should be carefully considered [10].

An alternative solution for drag reduction has been proposed in [11]. To use contrast wettability and the bubble accumulation on hydrophobic parts to reduce viscous resistance in microchannel flow has been investigated. Nanocoating may be deposited discretely on the surface of a microchannel that may allow to vary performance and stability of the flow resistance, since it allows fluid to slip in areas with a layer of bubbles, and to stick to portions without bubbles. The coating such as described in $[12,13]$ can be considered as a stable one.

In this paper calculations of the liquid flow rate and velocity depending on the slip length at the bottom wall have been done using the model proposed in [11], where the bubble size, channel height and slip length were the parameters of flow.

\footnotetext{
${ }^{\text {a } C o r r e s p o n d i n g ~ a u t h o r ~: ~ g l u z d o v 1 @ y a n d e x . r u ~}$
} 


\section{Problem statement and results}

It has been proposed to use the effect of concentration of gas bubbles on hydrophobic segments of the surface of the channel with contrast wettability for ensuring drag reduction [11]. Two regimes of flow with the concentration of bubbles in the hydrophobic region were analyzed. The first one is a regime without heating, where small gas bubbles in the flow precipitate in the hydrophobic region. The nanocoating ensured the contrast of wettability of about $20^{\circ}-25^{\circ}$ between the surface of the silicon plate and coating. The second regime was produced specially for the enhancement of the effect: a heater mounted beneath the hydrophobic region was switched on and the process of nucleation of bubbles began.

The scheme of the flow in microchannel is presented in Figure 1. $D$ - the length of the nanocoated section, $L$ - the length of the uncoated section, $P_{0}$ - inlet pressure, $P_{l}$ - outlet pressure, $H$ - channel height.

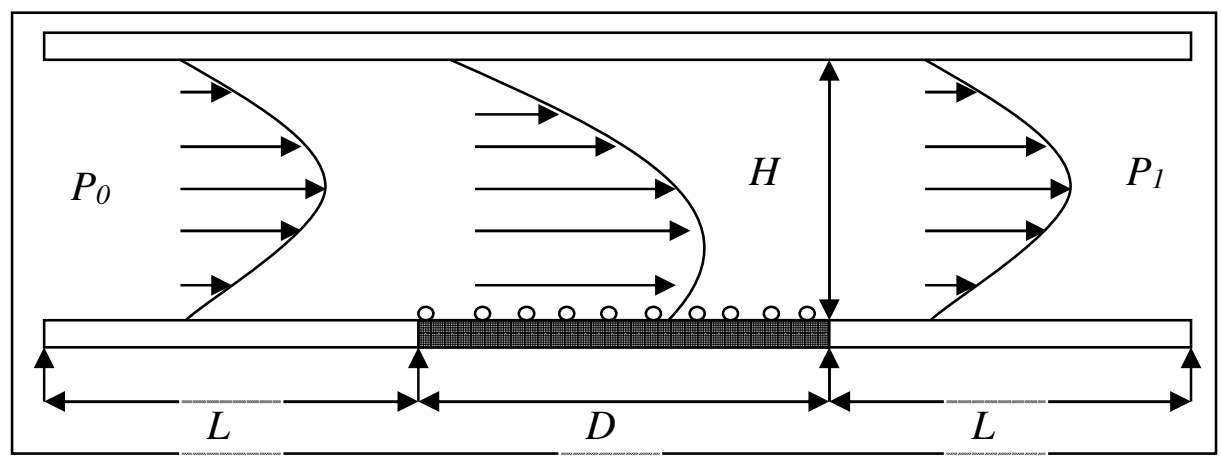

Figure 1. Sketch of the flow: $D$ - the length of the nanocoated section, $L$ - the length of the uncoated section, $P_{0}$ inlet pressure, $P_{I}$ - outlet pressure, $H$ - channel height.

Two-dimensional model of Poiseuille flow in microchannel with Navier slip condition is considered. The equation for the flow velocity is written as follows [11]:

$$
u=\frac{1}{2 \mu}{\frac{\partial P}{\partial x_{\beta}}}_{\beta}\left[y^{2}-y \frac{H^{2}-\delta^{2}+2 \delta \beta}{H-\delta+\beta}-H \frac{\beta(H-2 \delta)-\delta(H-\delta)}{H-\delta+\beta}\right],
$$

where

$\partial P / \partial x_{\beta}$ - pressure drop on section with slip condition,

$\beta$ - effective slip length,

$\mu$ - viscosity,

$\delta$ - the bubble size. 


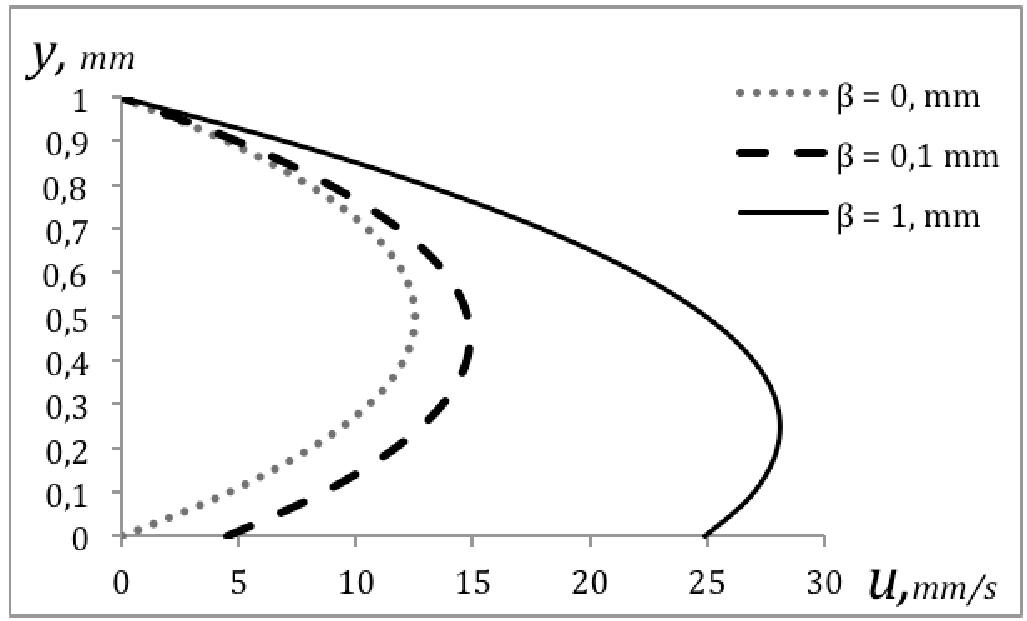

Figure 2. Velocity distribution for different effective slip length.

The dependence of the velocity distribution on the effective slip length is shown in Figure 2, where liquid is water, the channel height $H=1 \mathrm{~mm}$, bubbles size $\delta=1 \mu \mathrm{m}$, viscosity $\mu=0.001 \mathrm{~kg} / \mathrm{ms}$, pressure drop $\partial P / \partial x_{\beta}=100 \mathrm{~Pa} / \mathrm{m}$. Figure 2 shows how the flow front varies with the different slip length, $\beta$.

Figure 3 presents the flow rate depending on slip length. The dependence is not linear. When the slip length is $1 \mathrm{~mm}$, the flow rate is equal to $22 \mathrm{~mm}^{2} / \mathrm{s}$, which is significantly higher than the flow rate in the absence of slippage equal to $8.25 \mathrm{~mm}^{2} / \mathrm{s}$ (Figure 3). The surfaces with contrast wettability can increase the fluid flow rate at a fixed pressure gradient.

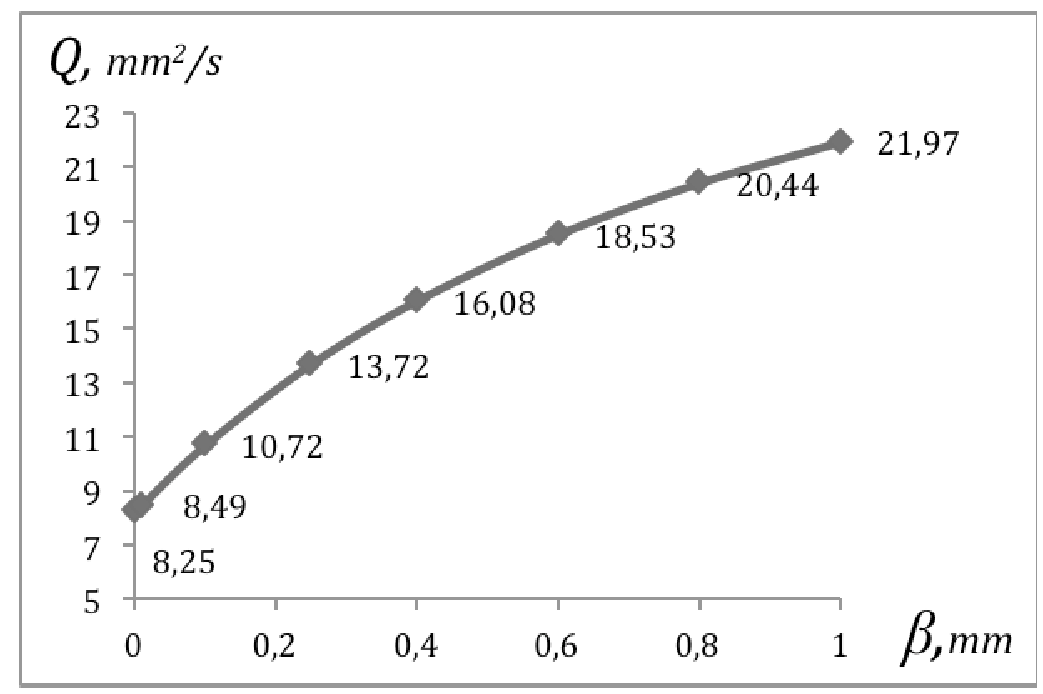

Figure 3. Flow rate for different effective slip length. 


\section{Acknowledgements}

This work was supported by a grant from the Russian Science Foundation (project 14-19-01755).

\section{References}

1. T. M. Squires and S. R. Quake, Reviews of Modern Physics, 77, 977 (2005)

2. H. A. Stone, A. D. Stroock, and A. Ajdari, Annual Reviews of Fluid Mechanics, 36, 381 (2004)

3. J. Ou, B. Perot, and J. P. Rothstein, Physics of Fluids, 16, 4635 (2004)

4. J.P. Rothstein, Annual Reviews of Fluid Mechanics, 42, 89 (2010)

5. O.A. Kabov, D.V. Zaitsev, Multiphase Science and Technology, 21, 249 (2009)

6. V.S. Ajaev, E.Ya. Gatapova, O.A. Kabov, Physics of Fluids, 25, 122102 (2013)

7. V.S. Ajaev, E.Ya. Gatapova, O.A. Kabov, Microgravity Science and Technology, 24 (1), 33 (2012)

8. V.S. Ajaev, E.Ya. Gatapova, O.A. Kabov, Physical Review E, 84 (4), 041606, (2011)

9. A.V. Belyaev, O.I. Vinogradova, Journal of Fluid Mechanics, 652, 489 (2010)

10. E. Karatay, A. S. Haase, C. W. Visser, C. Sun, D. Lohse, P. A. Tsai, and R. G. H. Lammertnik, Proceedings of the National Academy of Sciences of the United States of America, 110, 8422 (2013)

11. E.Ya. Gatapova, V.S. Ajaev, O.A. Kabov, JETP Letters, 101 (3), 160 (2015)

12. European Patent No. 2028432A1 (2009)

13. R. Rioboo, M. Marengo, S. Dall'Olio, M. Voue, and J. de Coninck, Langmuir 25 (11), 6005 (2009) 